\title{
Suppression of Kpnß1 expression inhibits human breast cancer cell proliferation by abrogating nuclear transport of Her2
}

\author{
CHENYI SHENG $^{1 *}$, JIAN QIU ${ }^{2 *}$, ZHIXIAN HE $^{1}$, HUA WANG $^{1}$, QINGQING WANG ${ }^{1}$, \\ ZENGYA GUO ${ }^{3}$, LIANXIN ZHU ${ }^{4}$ and QICHAO NI ${ }^{1}$ \\ ${ }^{1}$ Department of General Surgery, Affiliated Hospital of Nantong University; ${ }^{2}$ Medical School of Nantong University, \\ Nantong, Jiangsu 226001; ${ }^{3}$ Department of General Surgery, Tongzhou People's Hospital, Nantong, Jiangsu 226300; \\ ${ }^{4}$ Department of Surgical Oncology, Lu'an People's Hospital Tumor Center, The Lu'an Affiliated Hospital \\ of Anhui Medical University, Lu'an, Anhui 237000, P.R. China
}

Received April 6, 2017; Accepted October 23, 2017

DOI: $10.3892 /$ or.2017.6151

\begin{abstract}
Breast cancer (BC) is one of the most fatal diseases and poses critical health problems worldwide. However, its mechanisms remain unclear. Consequently, there is an urgency to investigate the mechanisms involved in $\mathrm{BC}$ initiation and progression and identify novel therapeutics for its prevention and treatment. In this study, we identified karyopherin $\beta-1$ (Kpn $\beta 1)$ as a possible novel therapeutic target for BC. Western blotting was used to evaluate the expression of Kpn $\beta 1$ in four pairs of tumorous and adjacent non-tumorous tissues. The results revealed that the protein level of $\mathrm{Kpn} \beta 1$ was higher in the cancer samples compared with those in the corresponding normal samples. Immunohistochemistry was performed on $140 \mathrm{BC}$ cases and indicated that $\mathrm{Kpn} \beta 1$ was significantly associated with clinical pathological variables. Kaplan-Meier curve revealed that high expression of $\mathrm{Kpn} \beta 1$ was related to poor BC patient prognosis. A starvation and re-feeding assay was used to imitate the cell cycle using the SKBR-3 cell line, indicating that $\mathrm{Kpn} \beta 1$ plays a critical role in cell proliferation. The Cell Counting Kit-8 assay revealed that SKBR-3 cells treated with Kpn $\beta 1$-siRNA ( $\operatorname{siKpn} \beta 1$ ) grew more slowly than the control cells, while flow cytometry revealed that low-Kpn $\beta 1$ expressing SKBR-3 cells exhibited increased BC cell apoptosis. Furthermore, the interaction between Kpn $\beta 1$ and Her2 was clearly observed by immunoprecipitation, indicating that Kpn $\beta 1$-knockdown abrogated nuclear transport of Her2. In
\end{abstract}

Correspondence to: Professor Qichao Ni, Department of General Surgery, Affiliated Hospital of Nantong University, Nantong, Jiangsu 226001, P.R. China

E-mail: nqcuser@163.com

*Contributed equally

Key words: $\mathrm{Kpn} \beta 1$, breast cancer, proliferation, nuclear transport, Her2 summary, our findings revealed that $\mathrm{Kpn} \beta 1$ is involved in the progression of $\mathrm{BC}$ and may be a useful therapeutic target.

\section{Introduction}

Breast cancer (BC) is the most commonly diagnosed cancer among women worldwide and a leading cause of cancerrelated mortality in developed countries (1). According to recent research, $\mathrm{BC}$ has risen to have the second highest mortality rate among cancers (2). As a disease with a complex, multifarious genetic and biochemical background, the exact mechanisms of breast carcinogenesis remain unclear. Hence, screening for more useful prognostic and predictive markers that contribute to $\mathrm{BC}$ progression is urgently needed to identify more effective therapies.

Karyopherin (Kpn) proteins, all of which have an N-terminal RanGTP-binding domain, a C-terminal cargobinding domain, and the capacity to bind components of the nuclear pore complex (NPC), are nuclear transport receptors that function in transporting cargo proteins and certain RNAs into and out of the cell nucleus via the NPC (3). Nuclear import via Kpn $\beta-1(\mathrm{Kpn} \beta 1)$ can occur either by $\mathrm{Kpn} \beta 1$ acting as an autonomous nuclear transport receptor, or through its association with an adaptor protein, such as Kpno (also known as importin alpha), in which case the import process is known as classical nuclear import (4). Kpn $\beta 1$ is involved in importing proteins, such as receptor tyrosine kinase 2 (ErbB-2) (5), epidermal growth factor receptor (EGFR) (6), and fibroblast growth factor 1 (FGF1) (7). Furthermore, several studies have extended the role of Kpn proteins in the regulation of the cell cycle, mitosis, and replication (8). Notably, recent studies revealed that Kpn proteins also have a key role in various cancers. For example, Kpn $\alpha 2$ expression was found to be associated with gastric cancer (9), prostate cancer (10), epithelial ovarian carcinoma (11), BC (12), endometrial cancer (13), hepatocellular carcinoma (14) and esophageal squamous cell carcinoma (15). Furthermore, Kpn expression was found to be associated with several malignant tumors such as cervical cancer (16), malignant peripheral nerve sheath tumors (17), and head, neck and lung cancer (18). Accordingly, Kpn $\beta 1$ exhibits clear potential as an anticancer therapeutic target (19). 
Although Kpn has been reported to be involved in chromosome stability in BC patients (20), there is no report demonstrating the function and mechanism of Kpn in the progression and prognosis of $\mathrm{BC}$, to the best of our knowledge.

The tyrosine kinase receptor Her2 is amplified in $20-30 \%$ of human cancers and its overexpression has been associated with poor patient prognosis (21). Recently, evidence has highlighted that nuclear Her2 may play a more aggressive role during tumor progression (22). Nuclear Her2 has been determined to act as a transcription factor for genes such as cyclin D1, FGF2 and cyclooxygenase-2 (COX-2) (5). Despite recent research on the translocation of Her2 to the nucleus, the mechanism by which Her2 travels from the cell surface to the nucleus is unclear.

In this study we focused on Kpn $\beta 1$ expression in primary and $\mathrm{BC}$ cell lines, its association with clinicopathological features, and its prognostic value for BC patient survival. This study provided evidence for a role of $\mathrm{Kpn} \beta 1$ in contributing to $\mathrm{BC}$ phenotype. Furthermore, we investigated the possible role of Kpn $\beta 1$ in the proliferation and apoptosis of BC cell lines. Based on our findings, we suggest that Kpn $\beta 1$ could be a novel therapeutic target for $\mathrm{BC}$.

\section{Materials and methods}

Patients and tissue samples. BC sections were obtained from 140 patients who had undergone breast surgical resection at the Department of General Surgery of the Affiliated Hospital of Nantong University between April 2002 and May 2010. The tissues had been formalin-fixed and paraffin-embedded for pathological diagnosis and immunohistochemical study and were authenticated histologically. The TNM tumor staging and histological grade were performed according to the World Health Organization guidelines. Patient information corresponding with these tissues was subsequently obtained from return patient visits to the hospital and telephone contact. The clinical features of all the patients, including age, tumor size, histologic grade, axillary lymph node status, and histology are shown in Table I. Fresh BC and normal tissue samples were immediately frozen in liquid nitrogen after surgical resection and maintained at $-80^{\circ} \mathrm{C}$. All human tissues were collected using protocols approved by the Ethics Committee of the Affiliated Cancer Hospital of Nantong University (Nantong, Jiangsu, China). The median patient age was 54 years (range, 34-88 years). The median 7-year follow-up time for the 140 patients was 30 months (range, 6-90 months). Histological grade was classified as follows: well-differentiated (grade I, $\mathrm{n}=17$ ), moderately differentiated (grade II, $n=60$ ), and poorly differentiated (grade III, $\mathrm{n}=63$ ). The majority of cases included infiltrating ductal carcinoma $(n=109,78 \%)$ and the remaining $22 \%$ of the cases consisted of other types. The main patient clinicopathological variables are shown in Table I. Informed consent was obtained from all patients.

Antibodies. All antibodies were sourced from Santa Cruz Biotechnology (Santa Cruz, CA, USA) unless otherwise specified. Antibodies for immunohistochemistry included anti-Kpnß1 (sc-11367, 1:200) and anti-Ki-67 (AB9260, 1:100; Millipore, Bedford, MA, USA); for western blot analysis they included anti-Kpn $\beta 1$ (1:500), anti-proliferating cell nuclear
Table I. Expression of Kpn $\beta 1, \mathrm{Ki}-67$ and clinicopathological parameters in 140 breast cancer specimens.

\begin{tabular}{|c|c|c|c|c|c|}
\hline \multirow[b]{2}{*}{ Parameters } & \multirow[b]{2}{*}{ Total } & \multicolumn{2}{|c|}{$\begin{array}{c}\text { Kpn } \beta 1 \\
\text { expression }\end{array}$} & \multirow[b]{2}{*}{ P-value ${ }^{a}$} & \multirow[b]{2}{*}{$\chi^{2}$} \\
\hline & & Low & High & & \\
\hline \multicolumn{6}{|l|}{ Age (years) } \\
\hline$\leq 50$ & 57 & 28 & 29 & 0.975 & 0.001 \\
\hline$>50$ & 83 & 41 & 42 & & \\
\hline \multicolumn{6}{|l|}{ Grade } \\
\hline I & 17 & 11 & 6 & $0.048^{\mathrm{a}}$ & 6.081 \\
\hline II & 60 & 34 & 26 & & \\
\hline III & 63 & 24 & 39 & & \\
\hline \multicolumn{6}{|l|}{ ER } \\
\hline Negative & 69 & 36 & 33 & 0.500 & 0.454 \\
\hline Positive & 71 & 33 & 38 & & \\
\hline \multicolumn{6}{|l|}{ PR } \\
\hline Negative & 70 & 34 & 36 & 0.866 & 0.029 \\
\hline Positive & 70 & 35 & 35 & & \\
\hline \multicolumn{6}{|l|}{ Her2 } \\
\hline Negative & 68 & 38 & 30 & 0.129 & 2.203 \\
\hline Positive & 72 & 31 & 41 & & \\
\hline \multicolumn{6}{|l|}{ Tumor size } \\
\hline$\leq 2 \times 2 \times 2$ & 77 & 41 & 26 & $0.007^{\mathrm{a}}$ & 7.290 \\
\hline$>2 \times 2 \times 2$ & 63 & 28 & 45 & & \\
\hline \multicolumn{6}{|c|}{$\begin{array}{l}\text { Axillary lymph } \\
\text { node status }\end{array}$} \\
\hline No & 52 & 31 & 21 & 0.060 & 3.532 \\
\hline $\mathrm{Nx}$ & 88 & 38 & 50 & & \\
\hline \multicolumn{6}{|c|}{$\begin{array}{l}\text { Nerve invasion } \\
\text { and metastasis }\end{array}$} \\
\hline Negative & 85 & 45 & 40 & 0.282 & 1.157 \\
\hline Positive & 55 & 24 & 31 & & \\
\hline \multicolumn{6}{|c|}{ Vascular metastasis } \\
\hline Negative & 75 & 42 & 33 & 0.088 & 2.914 \\
\hline Positive & 65 & 27 & 38 & & \\
\hline \multicolumn{6}{|l|}{ Histology } \\
\hline Ductal & 109 & 59 & 50 & $0.032^{\mathrm{a}}$ & 4.619 \\
\hline Others & 31 & 10 & 21 & & \\
\hline \multicolumn{6}{|l|}{$\mathrm{Ki}-67$} \\
\hline Low & 49 & 18 & 31 & $0.015^{\mathrm{a}}$ & 5.894 \\
\hline High & 91 & 38 & 53 & & \\
\hline
\end{tabular}

aStatistical analyses were performed by Pearson's $\chi^{2}$ test. $\mathrm{P}<0.05$ was considered as statistically significant. $\mathrm{Kpn} \beta 1$, karyopherin $\beta-1$; ER, estrogen receptor; PR, progesterone receptor.

antigen (PCNA; 1:1,000), anti- $\beta$-actin antibody $(1: 1,000)$, anti-cyclin D1 antibody $(1: 1,000)$ and anti-GAPDH (sc-7196, $1: 1,000)$; and for immunofluorescent staining they included anti-Kpn $\beta 1$ (1:500), anti-Her2 (1:400), and anti-actin monoclonal antibody $(1: 1,000)$. 
Immunohistochemical staining. In brief, tissue slices were dewaxed in xylene, rehydrated in graded ethanol and endogenous peroxidase activity was blocked by steeping in $3 \%$ methanolic peroxide for $20 \mathrm{~min}$. The sections were then heated to $121^{\circ} \mathrm{C}$ in an autoclave for $10 \mathrm{~min}$ in $0.1 \mathrm{M}$ citrate buffer $(\mathrm{pH} 6.0)$ to retrieve the antigen. After being rinsed in phosphate-buffered saline (PBS, $\mathrm{pH}$ 7.2) for $5 \mathrm{~min}$ (three times), tissue sections were incubated with the rabbit anti-human Kpn $\beta 1$ antibody (diluted 1:200) and the mouse anti-human $\mathrm{Ki}-67$ antibody (diluted 1:500) for $3 \mathrm{~h}$ at room temperature. After being washed with PBS, the peroxidase reaction was visualized by incubating the sections with DAB [0.1\% phosphate-buffered solution (PBS), $0.02 \%$ diaminobenzidine tetrahydrochloride, and $3 \% \mathrm{H}_{2} \mathrm{O}_{2}$ ]. Finally, the sections were counterstained with hematoxylin, dehydrated through graded alcohol, and mounted under a cover slip after being rinsed in water.

Immunohistochemical evaluation. All immunostained sections were randomly evaluated by three independent observers in a blinded manner using a Leica fluorescence microscope (Leica Microsystems GmbH, Wetzlar, Germany). Five fields of view were chosen per slide and at least 500 cells were counted per view at high power. To evaluate the immunoreaction of Kpn $\beta 1$, the staining intensity was estimated in comparison to the control and scored as follows: I, the reaction was not easily perceived from the background or $<5 \%$ of tumor cells were stained; II, 5-30\% of tumor cells were positively stained; and III, $>30 \%$ of tumor cells were positively-stained (Xue et al, 2013).

Western blot analysis. Before immunoblotting, tissues were immediately homogenized in lysis buffer [1\% NP-40, $50 \mathrm{mmol} / 1$ Tris (pH 7.5), $5 \mathrm{mmol} / 1$ EDTA, 1\% SDS, 1\% sodium deoxycholate, $1 \%$ Triton X-100, $1 \mathrm{mmol} / 1 \mathrm{PMSF}$, $10 \mathrm{mg} / \mathrm{ml}$ aprotinin and $1 \mathrm{mg} / \mathrm{ml}$ leupeptin] and the cells were washed three times with ice-cold PBS and resuspended in $2 \mathrm{X}$ lysis buffer $(50 \mathrm{mM}$ Tris- $\mathrm{HCl}, 120 \mathrm{mM} \mathrm{NaCl}, 0.5 \%$ NP-40, $100 \mathrm{mM} \mathrm{NaF}, 200 \mathrm{mM} \mathrm{Na} \mathrm{VO}_{4}$, and protease inhibitor mixture). The cells were then denatured at $100^{\circ} \mathrm{C}$ for $15 \mathrm{~min}$. Total protein concentration was then determined with a Bio-Rad protein assay (Bio-Rad Laboratories, Hercules, CA, USA). All protein samples were stored at $-20^{\circ} \mathrm{C}$. For sodium dodecyl sulfate-polyacrylamide gel electrophoresis (SDS-PAGE), samples were denatured at $100^{\circ} \mathrm{C}$ for $3 \mathrm{~min}$. The proteins were then separated with SDS-PAGE and subsequently transferred to polyvinylidene difluoride filter (PVDF) membranes (Millipore). The membranes were then blocked in 5\% skimmed-milk in Tris-buffered saline-Tween (TBST: $20 \mathrm{mM}$ Tris, $150 \mathrm{mM} \mathrm{NaCl}, 0.05 \%$ Tween-20) for $2 \mathrm{~h}$ at room temperature, and then incubated with primary antibodies overnight at $4^{\circ} \mathrm{C}$ for $6-8 \mathrm{~h}$ at room temperature. The membranes were then washed with TBST three times $(5 \mathrm{~min} /$ wash) and incubated with horseradish peroxidase-linked IgG secondary antibodies for $2 \mathrm{~h}$ at room temperature. The protein bands were detected using the enhanced chemiluminescence (ECL) detection system (Pierce, Rockford, IL, USA) and the band intensities were assessed using ImageJ analysis software (Wayne Rasband; National Institutes of Health, Bethesda, MD, USA).
Cell culture and cell cycle analysis. Two human BC cell lines, SKBR-3 and MDA-MB-231, were obtained from the Cell Bank of the Chinese Academy of Sciences (Shanghai, China) and used in this study. The MDA-MB-231 cell line was maintained in Dulbecco's modified Eagle's medium (DMEM; Gibco-BRL, Grand Island, NY, USA) supplemented with $10 \%$ heat-inactivated fetal bovine serum (HI-FBS), $2 \mathrm{mM}$ L-glutamine, and $100 \mathrm{U} / \mathrm{ml}$ penicillin-G and incubated at $37^{\circ} \mathrm{C}$ and $5 \% \mathrm{CO}_{2}$. The SKBR-3 cell line was maintained in Mccoy's 5A medium (Gibco-BRL) supplemented with $10 \%$ HI-FBS, $2 \mathrm{mM}$ L-glutamine, and $100 \mathrm{U} / \mathrm{ml}$ penicillin-G and incubated at $37^{\circ} \mathrm{C}$ and $0 \% \mathrm{CO}_{2}$.

Starvation and re-feeding was used to imitate the cell cycle. First, DMEM or Mccoy's 5A medium without FBS was used to incubate the MDA-MB-231 or SKBR-3 cells, respectively, for $48 \mathrm{~h}$ to synchronize cells, and was then replaced by complete medium. Subsequently, the cells were rapidly harvested at specified time-points and fixed in $70 \%$ ethanol for at least $24 \mathrm{~h}$ at $-20^{\circ} \mathrm{C}$, and then incubated with $1 \mathrm{mg} / \mathrm{ml}$ RNase A for $20 \mathrm{~min}$ at $37^{\circ} \mathrm{C}$. The cells were then stained with $0.5 \%$ Tween-20/propidium iodide (PI, $50 \mathrm{mg} / \mathrm{ml}$ ) in PBS and analyzed using a Becton-Dickinson flow cytometer (BD FACScan; Becton-Dickinson, San Jose, CA, USA) and CellQuest acquisition and analysis programs.

RNA interference of Kpn $\beta 1$. Small interference RNAs (siRNA) were designed and chemically synthesized by GeneChem (Shanghai, China). The Kpnß1-specific siRNA target sequences were as follows: Kpn $\beta 1$-siRNA\#0, 5'-GAGATCGAAGACTA ACAAA-3'; Kpnß1-siRNA\#1, 5'-CAGTGTAGTTGTTCGA GAT-3'; Kpn $\beta 1$-siRNA\#2, 5'-ACGAGAAGTCAAGAAC TAT-3'; and non-specific scrambled siRNA sequence, 5'-GCTGTTAGTGAGCTAAGTA-3'. Cells were transfected with $100 \mathrm{nmol} / \mathrm{l}$ of siRNA duplexes using Lipofectamine Plus reagent (Invitrogen, Carlsbad, CA, USA) according to the manufacturer's protocol.

Plate colony formation assay. SKBR-3 and MDA-MB-231 cells pretreated with Kpn $\beta 1$-siRNA and non-specific scrambled siRNA $(2,000$ cells/plate) were cultured in $5 \mathrm{ml}$ of DMEM supplemented with $10 \%$ FBS in a 6 -cm plate. After 14 days, the colonies were washed with PBS, fixed with methanol for $30 \mathrm{~min}$, and stained with crystal violet for $30 \mathrm{~min}$. Clearly visible colonies ( $>50 \mathrm{~mm}$ in diameter) were counted as positive for growth.

Cell proliferation assay. Cell Counting Kit-8 (CCK-8; Dojindo Laboratories, Kumamoto, Japan) was employed to assess cell proliferation. In brief, the cells were seeded into a 96-well cell culture cluster plate (Corning Incorporated, Corning, NY, USA) at a concentration of $2 \times 10^{4}$ cells/well in a volume of $100 \mu \mathrm{l}$ and grown overnight. The cells were then incubated with CCK- 8 reagents for $2 \mathrm{~h}$ at $37^{\circ} \mathrm{C}$ and the absorbance was quantified on an automated plate reader. Each condition was performed in triplicate and each experiment was repeated three times.

Flow cytometric analysis of cell apoptosis. SKBR-3 cells transfected with Kpn $\beta 1$-siRNA and control-siRNA were cultured for $48 \mathrm{~h}$ and harvested. Muse ${ }^{\mathrm{TM}}$ Annexin $\mathrm{V}$ and 
Normal
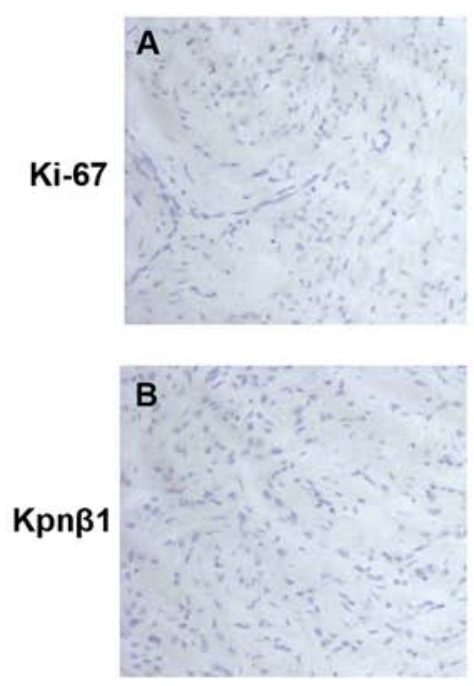

I
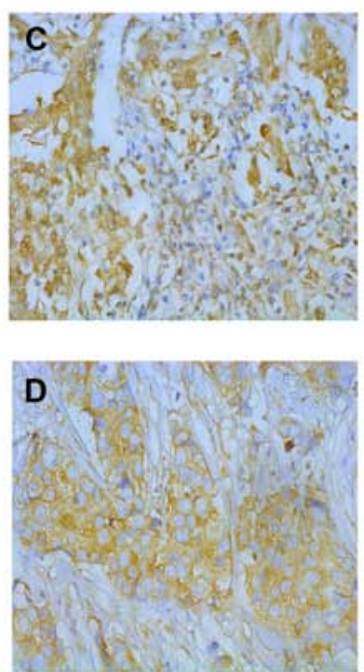

II
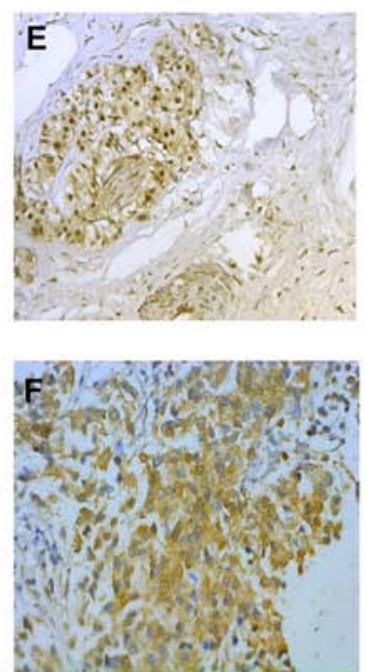

III
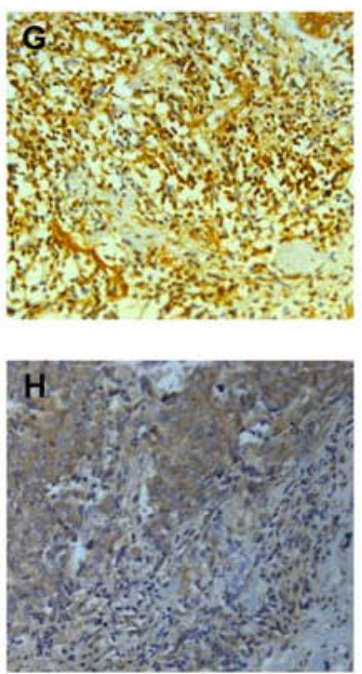

Figure 1. Immunohistochemical staining of Kpn $\beta 1$ and Ki-67 expression in paraffin-embedded BC tissues. (A and B) Kpn $\beta 1$ and Ki67 staining in BC tissues and adjacent normal tissues. Expression levels of Kpn $\beta 1$ and Ki-67 were (C and D) low (weakly positive) in grade I tissues; (E and F) moderate in grade II tissues; and $(\mathrm{G}$ and $\mathrm{H})$ high in grade III tissues. The images in A-H were captured at $\mathrm{x} 400$ magnification. BC, breast cancer; Kpn $\beta 1$, karyopherin $\beta-1$.

Dead Cell reagent (60 $\mu 1$, part no. 4700-1485, 100 tests/bottle) was then added to each tube with $60 \mu \mathrm{l}$ of cell suspension. After incubation for $20 \mathrm{~min}$ at room temperature in the dark, the apoptosis assay was performed using the Muse ${ }^{\mathrm{TM}}$ Cell Analyzer (Millipore) according to the manufacturer's instructions.

Coimmunoprecipitation. Cellular extracts were lysed in lysis buffer (150 mM NaCl, $1 \mathrm{mM}$ EDTA, $20 \mathrm{mM}$ Tris ( $\mathrm{pH} 7.5)$, $0.5 \%$ NP-40, $1 \mathrm{mM} \mathrm{NaF}, 1 \mathrm{mM} \mathrm{MNa} \mathrm{VO}_{4}, 1 \mathrm{mM}$ PMSF, and $2 \mathrm{~g} / \mathrm{ml}$ aprotinin) and incubated with primary antibodies at $4^{\circ} \mathrm{C}$ followed by incubation with protein $\mathrm{G}$-sepharose. The immunocomplexes were washed three times with lysis buffer. For single immunoprecipitation, the bound proteins were eluted by boiling the samples in SDS sample buffer containing 2-mercaptoethanol. For sequential double immunoprecipitation, the bound proteins were eluted from the sepharose beads by boiling for $3 \mathrm{~min}$ in 251 of SDS lysis buffer (20 mM Tris (pH 7.5), $50 \mathrm{mM} \mathrm{NaCl}, 1 \%$ SDS, and $1 \mathrm{mM}$ dithiothreitol). Samples were cooled and the supernatants were diluted with 2251 of lysis buffer containing the appropriate antibodies and incubated overnight at $4^{\circ} \mathrm{C}$. The immunocomplexes were then precipitated with protein A-Sepharose beads, washed with lysis buffer, and resuspended in SDS sample buffer. The eluted proteins were then boiled for $5 \mathrm{~min}$ and subjected to SDS-PAGE.

Immunofluorescent staining assay. Following prior treatment, the cells were fixed with paraformaldehyde for $40 \mathrm{~min}$ at room temperature, permeabilized for 15 min with $1 \%$ Triton-X, blocked for $2 \mathrm{~h}$ with $1 \% \mathrm{BSA}$ in PBS at $4^{\circ} \mathrm{C}$, and incubated overnight at $4^{\circ} \mathrm{C}$ with anti-Kpn $\beta 1$ monoclonal and anti-Her2 antibodies. The cells were then washed three times with PBS followed by incubation for $2 \mathrm{~h}$ with anti-rabbit IgG secondary antibody, anti-mouse $\operatorname{IgG}$ secondary antibody, or anti-actin monoclonal antibody. Nuclear staining was achieved with DAPI (4,6-diamidino-2-phenylindole; fluorescence) before mounting. After being washed with PBS, the slides were air-dried, mounted with anti-fading mounting reagent, and examined under a fluorescent microscope.

Statistical analysis. Data were analyzed by SPSS 17.0 software (SPSS, Inc., Chicago, IL, USA). Statistical significance of the correlations between Kpn $\beta 1$ and Ki-67 expression and the clinicopathological features were analyzed using the Chi-squared test. The Kaplan-Meier method was used to analyze survival curves and the log-rank test. Multivariate analysis was performed using Cox's proportional hazards model. The results are expressed as means \pm standard deviation (SD). $\mathrm{P}<0.05$ was considered to indicate a statistically significant result.

\section{Results}

The expression of Kpn $\beta 1$ and Ki-67 in human malignant breast tissues and cell lines. To identify whether Kpn $\beta 1$ was associated with BC, immunohistochemistry was applied to detect the expression and distribution of Kpn $\beta 1$ and Ki-67 in paraffin-embedded mammary tissue sections screened from 140 patients. For statistical analysis of Kpn $\beta 1$ and Ki-67 expression levels, we defined Kpn $\beta 1$ antibody specificity and scored Kpn $\beta 1$ staining as weakly positive (I), moderately positive (II), and strongly positive (III) based on the percentage of positively stained cells and staining intensity. When considering the characteristics of the data, we then classified group I as low expression and groups II and III as high expression. The results of these experiments revealed that $\mathrm{Kpn} \beta 1$ was mainly located in the cytoplasm with high expression of Kpn $\beta 1$ significantly consistent with high expression of nuclear Ki-67 (Fig. 1).

To verify whether Kpn $\beta 1$ is highly expressed in human $\mathrm{BC}$, we further detected the expression of $\mathrm{Kpn} \beta 1$ by western blot analysis in four pairs of fresh samples. As shown in Fig. $2 \mathrm{~A}$ and $\mathrm{B}$, the expression of Kpn $\beta 1$ was much higher in 
A

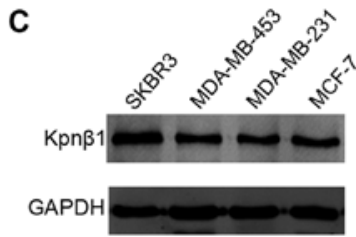

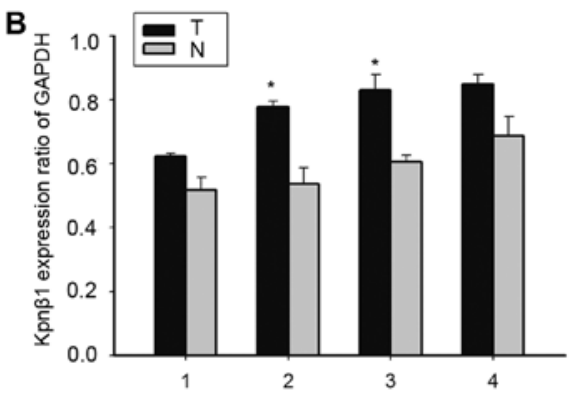

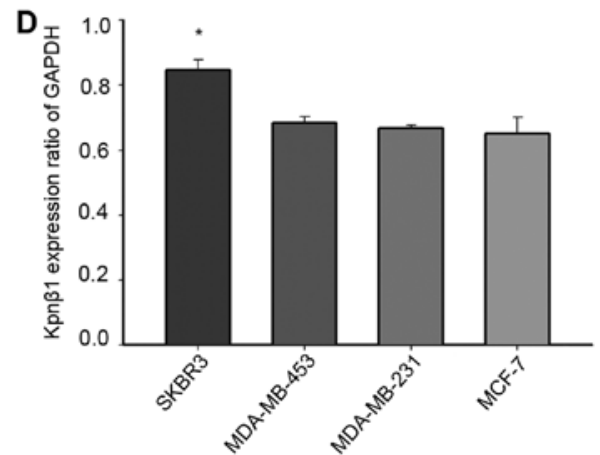

Figure 2. Kpn $\beta 1$ expression in BC tissues. Kpn $\beta 1$ expression levels in four paired adjacent normal and breast carcinoma tissues assessed by (A) western blotting and (B) density photometry. Expression of Kpn $\beta 1$ in four BC cell lines analyzed by (C) western blotting and (D) density photometry. The data from each time point were derived from three independent experiments. ${ }^{*} \mathrm{P}<0.05$. T, tumor; $\mathrm{N}$, adjacent normal tissues; $\mathrm{BC}$, breast cancer; Kpn $\beta 1$, karyopherin $\beta-1$.
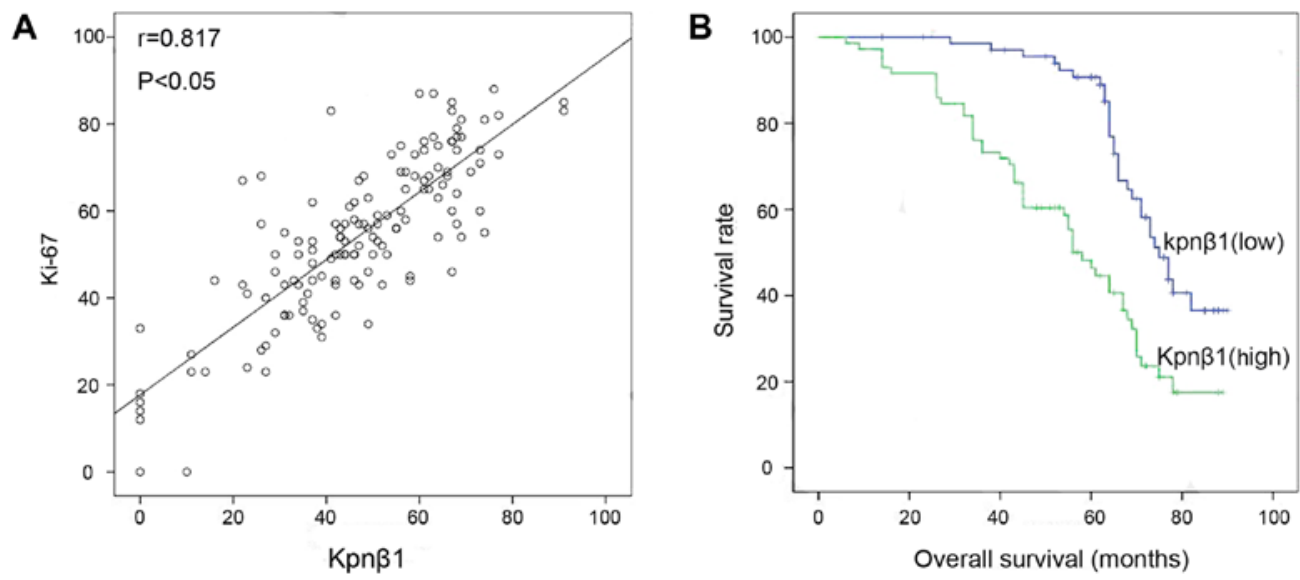

Figure 3. (A) The relationship between the Ki-67 proliferation index and Kpn $\beta 1$ expression in breast carcinoma tissues. Scatter plot of Ki-67 vs/ Kpn $\beta 1$ expression, with a regression line showing a significant correlation according to Spearman's correlation coefficient. (B) Association of Kpn $\beta 1$ with patient prognosis in BC. Kaplan-Meier survival curves revealed that low expression of $\mathrm{Kpn} \beta 1$ is correlated with long-term survival. BC, breast cancer; Kpn $\beta 1$, karyopherin $\beta-1$.

malignant tumors when compared with that noted in the adjacent normal tissues, consistent with our previous observation. To further detect the expression of $\mathrm{Kpn} \beta 1$ in $\mathrm{BC}$ cell lines, we selected SKBR-3, MDA-MB-453, MCF-7, and MDA-MB-231 cells. Kpn $\beta 1$ was expressed to a greater extent in SBKR-3 cells compared with the other cell lines (Fig. 2C and D). SKBR-3 cells were therefore used for subsequent experimentation. We supposed that the expression of $\mathrm{Kpn} \beta 1$ may be related to the proliferation of $\mathrm{BC}$ based on these results.

The relevance of Kpn $\beta 1$ expression with clinicopathological variables and BC patient survival. To further examine the pathophysiological significance of $\mathrm{Kpn} \beta 1$ with respect to tumor characteristics and behavior, the clinicopathological data were summarized and are shown in Table I. We found that Kpn $\beta 1$ expression was markedly correlated with grade $(\mathrm{P}=0.048)$, tumor size $(\mathrm{P}=0.007)$, histology $(\mathrm{P}=0.032)$, and Ki-67 expression $(\mathrm{P}=0.015)$. Whereas there was no association between Kpn $\beta 1$ and age $(\mathrm{P}=0.975)$, estrogen receptor $(\mathrm{ER})$ $(\mathrm{P}=0.500)$, progesterone receptor $(\mathrm{PR})(\mathrm{P}=0.866)$, Her2 expression $(\mathrm{P}=0.129)$, axillary lymph node status $(\mathrm{P}=0.060)$, nerve invasion and metastasis $(\mathrm{P}=0.282)$ and vascular metastasis $(\mathrm{P}=0.088)$. Furthermore, the relationship between the $\mathrm{Ki}-67$ proliferation index and $\mathrm{Kpn} \beta 1$ expression in breast carcinoma tissues revealed a significant correlation according to Spearman's correlation coefficient (Fig. 3A). We next sought to understand the correlation between $\mathrm{Kpn} \beta 1$ expression level and patient survival using Kaplan-Meier analysis. At the end 
Table II. Survival status and clinicopathological parameters of the 140 breast carcinomas specimens.

\begin{tabular}{|c|c|c|c|c|c|}
\hline \multirow[b]{2}{*}{ Parameters } & \multirow[b]{2}{*}{ Total } & \multicolumn{2}{|c|}{$\begin{array}{c}\text { Survival } \\
\text { status }\end{array}$} & \multirow[b]{2}{*}{ P-value ${ }^{a}$} & \multirow[b]{2}{*}{$\chi^{2}$} \\
\hline & & Alive & Dead & & \\
\hline \multicolumn{6}{|l|}{ Age (years) } \\
\hline$\leq 50$ & 57 & 22 & 35 & 0.325 & 0.968 \\
\hline$>50$ & 83 & 39 & 44 & & \\
\hline \multicolumn{6}{|l|}{ Grade } \\
\hline I & 17 & 13 & 4 & $0.004^{\mathrm{a}}$ & 11.310 \\
\hline II & 60 & 28 & 32 & & \\
\hline III & 63 & 20 & 43 & & \\
\hline \multicolumn{6}{|l|}{ ER } \\
\hline Negative & 69 & 35 & 34 & 0.092 & 2.832 \\
\hline Positive & 71 & 26 & 45 & & \\
\hline \multicolumn{6}{|l|}{ PR } \\
\hline Negative & 70 & 30 & 40 & 0.865 & 0.029 \\
\hline Positive & 70 & 31 & 39 & & \\
\hline \multicolumn{6}{|l|}{ Her2 } \\
\hline Negative & 68 & 28 & 40 & 0.579 & 0.308 \\
\hline Positive & 72 & 33 & 39 & & \\
\hline \multicolumn{6}{|l|}{ Tumor size } \\
\hline$\leq 2 \times 2 \times 2$ & 77 & 33 & 34 & 0.194 & 1.687 \\
\hline$>2 \times 2 \times 2$ & 63 & 28 & 45 & & \\
\hline \multicolumn{6}{|c|}{$\begin{array}{l}\text { Axillary lymph } \\
\text { node status }\end{array}$} \\
\hline NO & 52 & 34 & 18 & $0.000^{\mathrm{a}}$ & 16.010 \\
\hline $\mathrm{Nx}$ & 88 & 27 & 61 & & \\
\hline \multicolumn{6}{|c|}{$\begin{array}{l}\text { Nerve invasion } \\
\text { and metastasis }\end{array}$} \\
\hline Negative & 85 & 46 & 39 & $0.002^{\mathrm{a}}$ & 9.788 \\
\hline Positive & 55 & 15 & 40 & & \\
\hline \multicolumn{6}{|c|}{ Vascular metastasis } \\
\hline Negative & 75 & 48 & 27 & $0.000^{\mathrm{a}}$ & 27.419 \\
\hline Positive & 65 & 13 & 52 & & \\
\hline \multicolumn{6}{|l|}{ Histology } \\
\hline Ductal & 109 & 50 & 59 & 0.303 & 1.059 \\
\hline Others & 31 & 11 & 20 & & \\
\hline \multicolumn{6}{|l|}{ Ki-67 } \\
\hline Low & 49 & 28 & 21 & $0.017^{\mathrm{a}}$ & 5.647 \\
\hline High & 91 & 33 & 58 & & \\
\hline \multicolumn{6}{|l|}{ Kpn $\beta 1$} \\
\hline Low & 69 & 39 & 30 & $0.002^{\mathrm{a}}$ & 9.281 \\
\hline High & 71 & 22 & 49 & & \\
\hline
\end{tabular}

astatistical analyses were performed by Pearson's $\chi^{2}$ test. $\mathrm{P}<0.05$ was considered as statistically significant. $\mathrm{Kpn} \beta 1$, karyopherin $\beta-1$; ER, estrogen receptor; $\mathrm{PR}$, progesterone receptor.

of the clinical follow-up, survival analysis was restricted to 140 patients with complete follow-up data and results for
Table III. Contribution of various potential prognostic factors to survival by Cox regression analysis in 140 breast carcinoma specimens

\begin{tabular}{lccc}
\hline Parameters & Hazard radio & $95.0 \%$ CI & P-value \\
\hline Kpn $\beta 1$ & 2.925 & $1.716-4.984$ & $0.001^{\mathrm{a}}$ \\
Ki-67 & 0.861 & $0.496-1.495$ & 0.596 \\
Age (years) & 0.919 & $0.569-1.483$ & 0.729 \\
Histology & 0.698 & $0.402-1.210$ & 0.200 \\
Grade & 2.121 & $1.384-3.251$ & $0.001^{\mathrm{a}}$ \\
ER & 0.992 & $0.541-1.821$ & 0.980 \\
PR & 1.207 & $0.653-2.230$ & 0.548 \\
Her2 & 0.554 & $0.320-0.959$ & $0.035^{\mathrm{a}}$ \\
Tumor size & 0.792 & $0.487-1.288$ & 0.348 \\
Axillary lymph & 4.065 & $2.212-7.469$ & $0.001^{\mathrm{a}}$ \\
node status & & & \\
Nerve invasion & 1.078 & $0.635-1.829$ & 0.780 \\
and metastasis & & & \\
Vascular metastasis & 1.830 & $1.064-3.147$ & $0.029^{\mathrm{a}}$ \\
\hline
\end{tabular}

Statistical analyses were performed by the log-rank test. ${ }^{a} \mathrm{P}<0.05$ was considered as statistically significant. CI, confidence interval; Kpn $\beta 1$, karyopherin $\beta$-1; ER, estrogen receptor; PR, progesterone receptor.

Kpn $\beta 1$ expression by immunohistochemistry. Kaplan-Meier survival curves revealed that high expression of Kpn $\beta 1$ was significantly associated with poor overall survival (Fig. 3B). In addition, in the univariate analysis, when all variables were compared separately to survival status, tumor grade $(\mathrm{P}=0.004)$, axillary lymph node status $(\mathrm{P}=0.000)$, nerve invasion and metastasis $(\mathrm{P}=0.002)$, vascular metastasis $(\mathrm{P}=0.000)$, Ki-67 expression $(\mathrm{P}=0.017)$, and $\mathrm{Kpn} \beta 1$ expression $(\mathrm{P}=0.002)$ were prognostic factors for overall survival (Table II). Multivariate analysis using the Cox's proportional hazards model indicated that $\mathrm{Kpn} \beta 1$ expression $(\mathrm{P}=0.001)$, grade $(\mathrm{P}=0.001)$, Her2 expression $(\mathrm{P}=0.035)$, axillary lymph node status $(\mathrm{P}=0.001)$, and vascular metastasis $(\mathrm{P}=0.029)$ were independent prognostic indicators of overall survival (Table III).

Kpn $\beta 1$ expression is positively correlated with cell proliferation and its expression is cell-cycle dependent. Since the expression of Kpn $\beta 1$ was significantly correlated with $\mathrm{Ki}-67$ expression, a cellular marker for proliferation in $\mathrm{BC}$ specimens, we hypothesized that $\mathrm{Kpn} \beta 1$ may play a role in the cell cycle progression of $\mathrm{BC}$ cells. We demonstrated that the expression of $\mathrm{Kpn} \beta 1$ was high in $\mathrm{BC}$ cells, especially in SKBR-3 cells (Fig. 2C and D). To ascertain that Kpn $\beta 1$ was invovled in the cell cycle, SKBR-3 cells were subjected to serum starvation and re-feeding. Flow cytometric analysis revealed that after $48 \mathrm{~h}$ serum deprivation, SKBR-3 cells were arrested in the G1 phase (86.56\%). Upon re-feeding, the cells excited at the G1 phase and gradually entered $\mathrm{S}$ phase over time (Fig. 4A and B). We then employed western blotting to examine whether the expression of Kpn $\beta 1$ was cell-cycle dependent. Kpn $\beta 1$ expression was found to increase gradually after serum stimulation with increased time, consistent with the expression of the proliferation marker PCNA (Fig. 4C and D). 

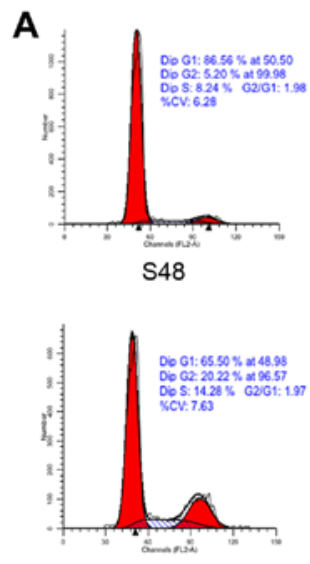

R8

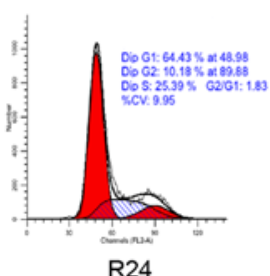

R24

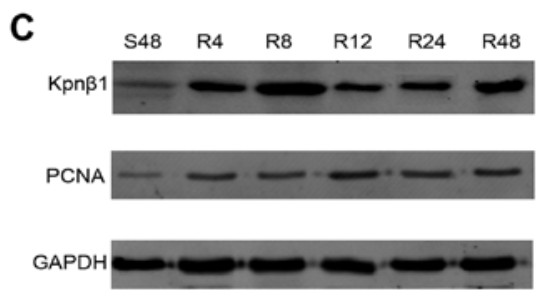

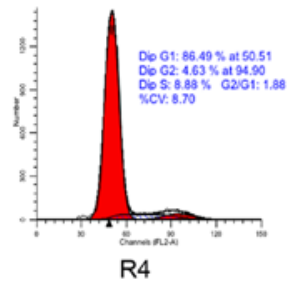

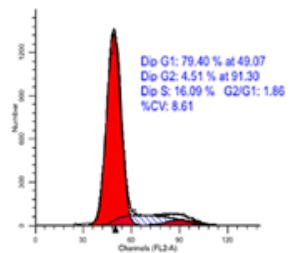

R12

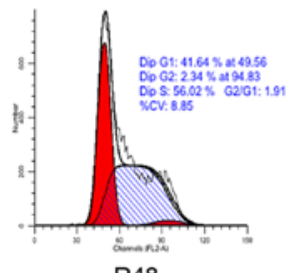

R48
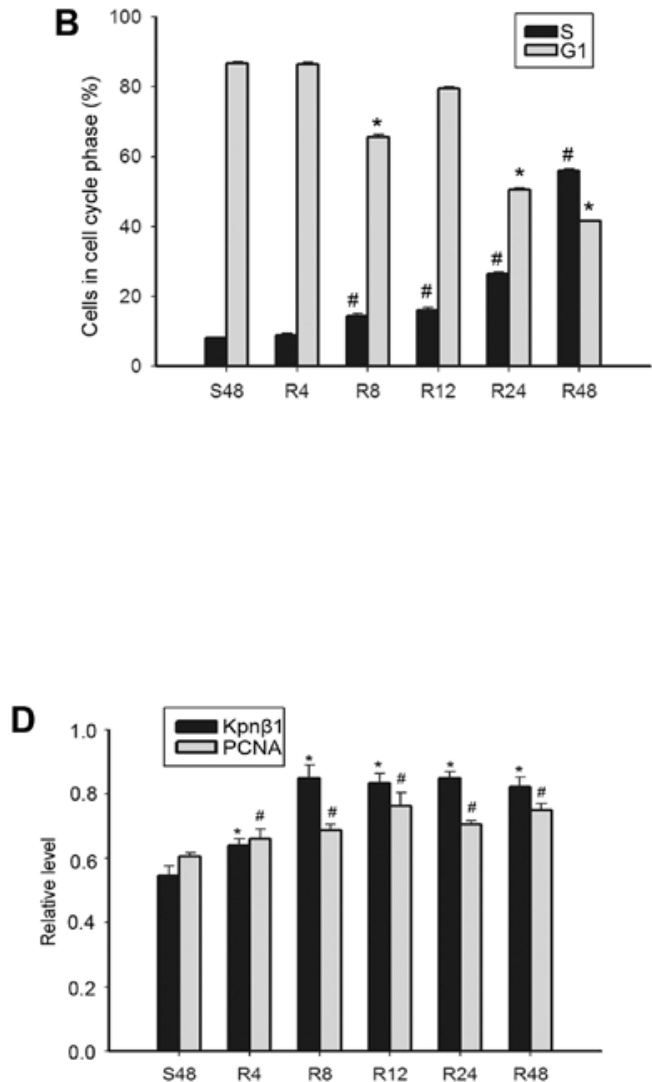

Figure 4. Expression of Kpn $\beta 1$ and cell cycle-related molecules detected in proliferating MDA-MB-231 cells by flow cytometry. (A and B) Cells synchronized at the phase G1 progressed into the cell cycle when serum was added for S48h, R4h, R8h, R12h, R24h, and R48h. (C and D) S48h MDA-MB-231 cells were released by re-feeding with serum and cell lysates were prepared and analyzed by western blotting using antibodies against Kpn $\beta 1$, PCNA, and GAPDH (loading control). Bar charts revealing the ratio of Kpn $\beta 1$, PCNA, and GAPDH by densitometry. Data are expressed or presented as the means \pm SEM. ${ }^{*}, \# \mathrm{P}<0.05$, compared with the control cells that were serum starved for $48 \mathrm{~h}(\mathrm{~S} 48 \mathrm{~h})$. SEM denotes the standard error of the mean. $\mathrm{S}$ denotes serum starvation. $\mathrm{R}$ denotes serum release. Kpn $\beta 1$, karyopherin $\beta$-1; PCNA, proliferating cell nuclear antigen.

These findings indicated that Kpn $\beta 1$ may play an important role in cell proliferation of SKBR-3 cells via involvement in the cell cycle.

Kpn $\beta 1$ knockdown inhibits cellular proliferation and promotes cell cycle arrest. To further verify the effect of Kpn $\beta 1$ on BC cell proliferation, chemically synthesized siRNA was employed to knock down endogenous Kpn $\beta 1$ in SKBR-3 cells. SKBR-3 cells were transfected with Kpn $\beta 1$-siRNA (siRNA-0, siRNA-1, siRNA-2) and negative control siRNA, and then the expression of Kpn $\beta 1$ was assessed by western blotting $48 \mathrm{~h}$ post-transfection (Fig. 5A). The results revealed that Kpn $\beta 1$ expression levels were decreased in the SKBR-3 cells transfected with Kpn $\beta 1$-siRNA compared with cells transfected with the negative control siRNA, with siRNA-2 achieving the most marked knockdown efficiency (Fig. 5A and B).

In the colony formation assay, we observed that SKBR-3 and MDA-MB-231 cell proliferation was significantly inhibited in the cells treated with siRNA-2, and was more significant in the SKBR-3 cells (Fig. 5C). This indicated that in SKBR-3 cells, the effect of Kpn $\beta 1$ on cell proliferation was more significant. Furthermore, the CCK-8 assay found that the rate of SKBR-3 cell proliferation after treatment with siRNA-2 exhibited a significant decline compared with the negative control siRNA (Fig. 5D). Additionally, flow cytometric analyses of the cell cycle in SKBR-3 cells transfected with different treatments revealed a significant increase in the G1 phase and a marked decrease in the $\mathrm{S}$ phase, suggesting that downregulation of Kpn $\beta 1$ arrested the cell cycle (Fig. 5E). Based on these findings, Kpn $\beta 1-k n o c k d o w n$ exhibited a specific inhibitory effect on cell proliferation associated with cell cycle arrest in the SKBR-3 cells.

Kpn $\beta 1$ interacts with Her 2 and suppression of Kpn $\beta 1$ expression abrogates Her 2 nuclear transport. Despite a lack of statistical correlation between the expression of Kpn $\beta 1$ and Her2 detected in our $140 \mathrm{BC}$ tissues $(\mathrm{P}=0.129)$, we investigated the association between Kpn $\beta 1$ and Her2. We hypothesized that Kpn $\beta 1$-knockdown may suppress BC cell proliferation by blocking Her2 nuclear entry, and we assessed 

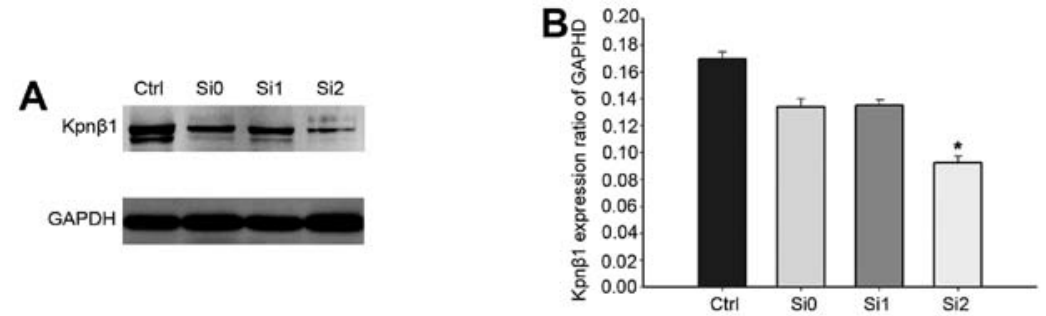

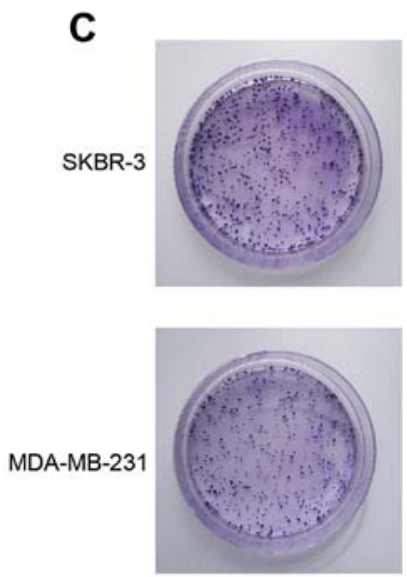

Ctrl
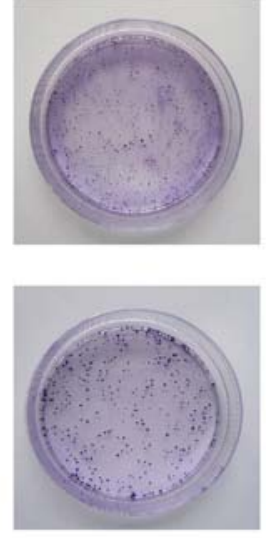

$\mathrm{Si} 2$
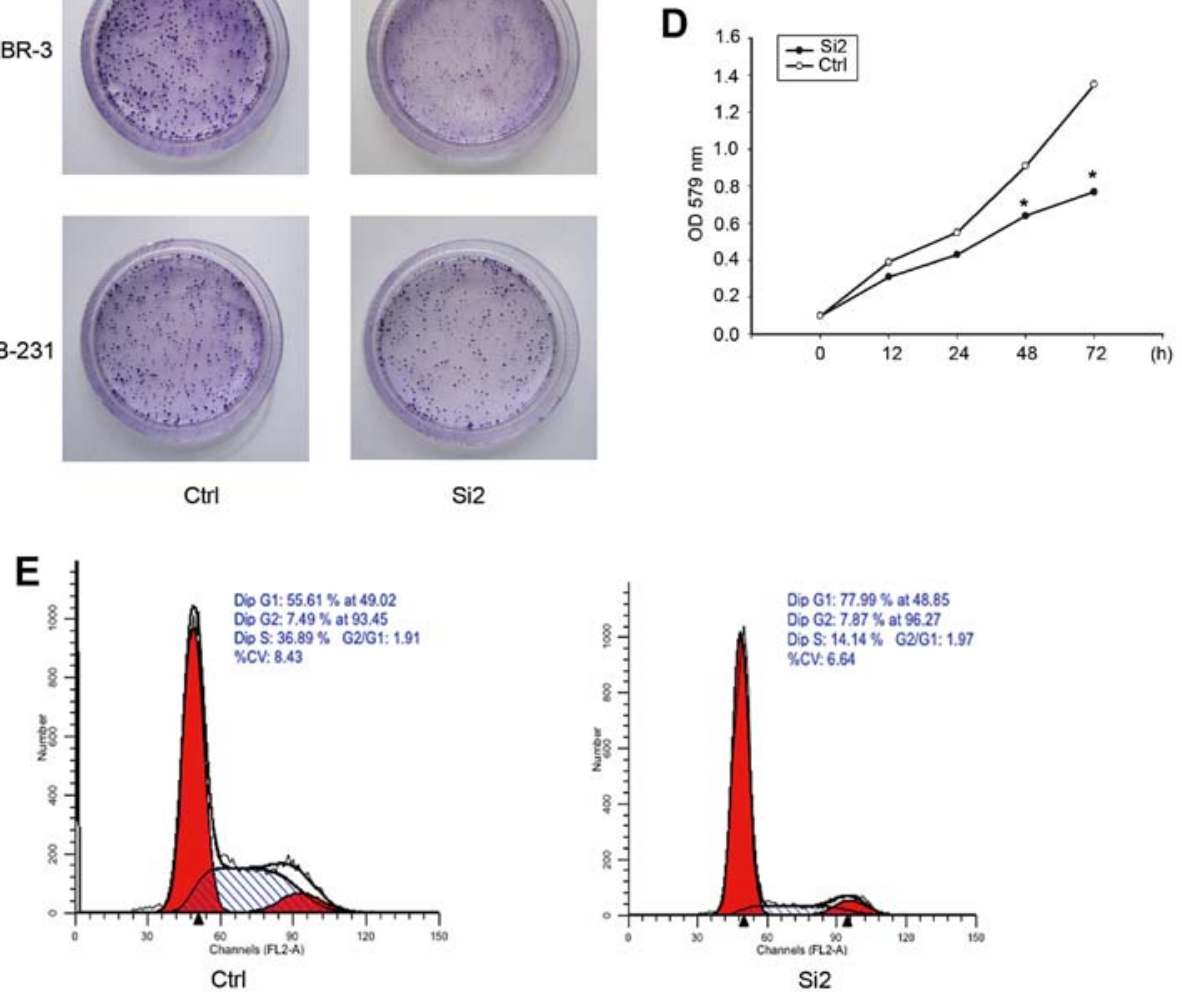
$48 \mathrm{~h}$ after transfection. Transfected cells were subjected to western blot analysis with antibodies against Kpn $\beta 1$ and GAPDH (loading control). (B) Bar chart revealing the ratio of $\mathrm{Kpn} \beta 1$ to GAPDH assessed by densitometry. Data are presented as the means $\pm \mathrm{SD},{ }^{*} \mathrm{P}<0.05$ compared with the control. (C) The selected and stably-transfected cells were cultivated into $6-\mathrm{cm}$ culture plates and incubated for 12 days at $37^{\circ} \mathrm{C}$ with $5 \% \mathrm{CO}_{2}$. Giemsa solution was used to observe diversity in the Kpn $\beta 1$-depleted cells. (D) Cell proliferation determined by the CCK-8 assay revealed that Kpn $\beta 1-k n o c k d o w n$ inhibited cell proliferation. CCK- 8 reagents were added to the medium and incubated for an additional $2 \mathrm{~h}$ and the absorbance was assessed at each of the indicated time-points $(0,12$, 24,48 and $72 \mathrm{~h}$ ). Data from each time-point were derived from three independent experiments. The data are presented as the means $\pm \mathrm{SD}$, ${ }^{*} \mathrm{P}<0.05$. (E) Kpn $\beta 1$ expression was knocked down in MDA-MB-231 cells transfected with Kpn $\beta 1$-siRNA\#2. The adherent cells were collected and examined by flow cytometry, which revealed a delay in G1-S transition and significant arrest at the G1 phase. Data are presented as the means \pm SD. The results are a combination of the data from three independent experiments. Kpn $\beta 1$, karyopherin $\beta-1$; CCK-8, Cell Counting Kit-8.

this using the SKBR-3 cell line (Her2-overexpressing cells) The results confirmed the effect of Kpn $\beta 1$ on Her 2 in SKBR-3 cells (Fig. 6A). Furthermore, immmunofluorescence detected co-localization of Kpn $\beta 1$ and Her2 in the SKBR-3 cell cytoplasm (Fig. 6B).

We next found that the localization of Her2 was affected by Kpn $\beta 1$-knockdown. When SKBR-3 cells were transfected with Kpn 31 -siRNA2, confocal microscopy demonstrated the distinct localization of Her2 in the cytoplasm and at the cell surface, but not in the nucleus as observed in the control siRNA-treated cells (Fig. 6C and D). These results indicated that Kpn $31-k n o c k d o w n$ abrogated nuclear transport of Her2. From the above mentioned results, we speculated that $\mathrm{Kpn} \beta 1$ stimulated cell proliferation by promoting the nuclear translo- cation of Her2. However, it was not determined whether cell proliferation depended on Her 2 status. Thus, we used trastuzumab to inhibit the activity of the cell membrane surface Her2. The results revealed the Her2 activities of different cases. Kpn $\beta 1$ knockdown also inhibited cellular proliferation (Fig. 6E). Therefore, Kpn $\beta 1$ interacted with Her2, then promoted nuclear transport of Her2, which was not dependent on the state of Her2.

\section{Discussion}

$\mathrm{BC}$ is the leading form of cancer in women, and although substantial progress has been made in its screening and management, globally it has the highest mortality rate (23). 

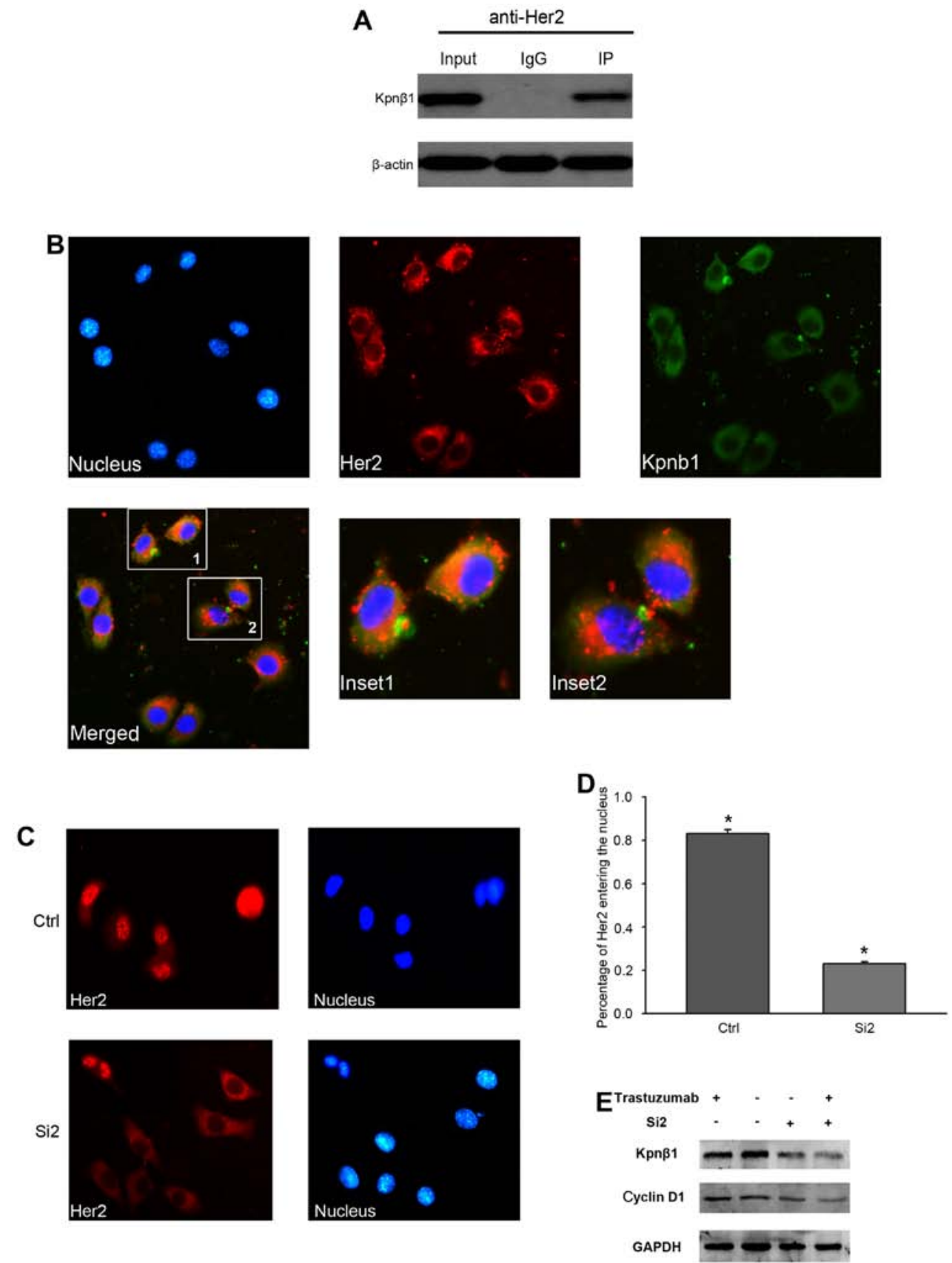

Figure 6. Kpn $\beta 1$ interacts with Her2 and suppression of Kpn $\beta 1$ expression abrogates nuclear transport of Her2. (A) SKBR-3 cells were immunoprecipitated (IP) with antibodies against Her2 or control IgG (IgG). The presence of $\mathrm{Kpn} \beta 1$ in the immunocomplexes was examined by immunoblotting analysis. Input was used as the positive control. (B) Kpn $\beta 1$ and Her2 colocalized in the cytoplasm and the nucleus of SKBR-3 cells as shown by immunofluorescence staining (insets 1 and 2, respectively). Images were then analyzed by confocal microscopy. Boxed areas are shown in detail in insets 1 and 2. (C) Immunofluorescence staining using anti-Her2 antibody in SKBR3 cells revealed that Her2 localization changed after knockdown of Kpn 31 expression (Si2). (D) Bar chart showing the percentage of Her2 entering the nucleus. Data are presented as the means $\pm \mathrm{SD},{ }^{*} \mathrm{P}<0.05$ compared with the control. (E) Western blotting analyzed the expression of cyclin D1 to confirm whether knockdown of Kpn $\beta 1$ or trastuzumab treatment affected the proliferation of the SKBR-3 cells. Kpn $\beta 1$, karyopherin $\beta-1$.

Although $\mathrm{BC}$ is presently incurable, it has the potential to become curable, or at least have improved prognostics when detected at an early stage. Thus a deeper understanding of the molecular events associated with BC is essential to develop novel treatments. In this study, we identified and characterized $\mathrm{Kpn} \beta 1$ as an important player in $\mathrm{BC}$ progression. $\mathrm{Kpn} \beta 1$ appears to be involved in the process of $\mathrm{BC}$ cell proliferation, partially by participating in the nuclear transport of Her2.

$\mathrm{Kpn} \beta 1$ functions as a transportation cargo protein into and out of the cell nucleus during a selective, multistep process (24).
Kpn $\beta 1$-mediated nuclear transportation is involved in multiple biological processes such as insulin resistance, circadian rhythm and viral infections. Kpn $\beta 1$ was found to promote palmitate-induced insulin resistance via NF- $\mathrm{KB}$ signaling in hepatocytes (25), and mediate PER/CRY nuclear translocation and therefore circadian clock function (26). Upregulation of $\mathrm{Kpn} \beta 1$ was effective in nuclear localization signaling for the minor capsid proteins, VP2 and VP3, during BKPyV nuclear entry (27). Moreover, Kpn $\beta 1$ likely plays a key role in the inflammation process (28). 
Studies on the effect of Kpn $\beta 1$ expression on tumors have been recently reported. There is a consensus that increased expression of certain $\mathrm{Kpn} \beta$ proteins in cancer cells results in increased nuclear transport efficiency, thus facilitating increased oncogenic signaling and promoting the cancer phenotype (19). Increased expression of Kpn $\beta 1$ was recognized in malignant $\mathrm{BC}$ cells and $\mathrm{Kpn} \beta 1$ knockdown has been shown to decrease nuclear import efficiency in malignant but not in non-transformed cells (29). Furthermore, previous studies have revealed that $\mathrm{Kpn} \beta 1$ is overexpressed in colon, breast, lung, ovarian, and cervical cancer specimens when compared with normal tissues (17).

Many articles exist on the close relationship between $\mathrm{Kpn} \beta 1$ expression and tumor proliferation, and Kpn $\beta 1$ inhibition has been shown to prolong mitotic arrest and apoptosis in cervical cancer cells (30). Furthermore, Kpn $\beta 1$ knockdown abrogated nuclear transport of DR5 and increased its cell surface expression. Kpnß1-mediated nuclear localization of DR5 limited DR5/TRAIL-induced cell death of human tumor cells (31), suggesting that the molecular mechanism of Kpn $\beta 1$ and tumor proliferation was related to its mediated nuclear entry efficiency. Therefore, inhibition of Kpn $\beta 1$ represents a novel therapeutic approach for the treatment of cancer (32).

A previous study reported that the regulation of Kpn $\beta 1$ expression in cancer cells was related to the level of EZH2/ miR-30a. Inhibition of E2F in cancer cells caused increased activation of Kpn $\beta 1$ promoters, leading to elevated levels of $\mathrm{Kpn} \beta 1$ proteins, and ultimately impacting the phenotype in cervical carcinoma (33). In malignant peripheral nerve sheath tumor (MPNST) cells, EZH2 expression was significantly upregulated and the miR-30a level was significantly increased in EZH2-knockdown cells, which may inhibit the expression of Kpn $\beta 1$. Based on this, EZH2 regulated miR-30a targeted Kpn $\beta 1$ in MPNST cells (34). However, limited studies exist describing the overexpression of $\mathrm{Kpn} \beta 1$ in BC. Consequently the molecular mechanism of Kpn $\beta 1$ remains unclear.

In our study, the expression of Kpn $\beta 1$ in SKBR-3 cells was higher than that in MDA-MB-231 cells (Fig. 2C). Although siRNA induced inhibition of $\mathrm{Kpn} \beta 1$ in both cell lines, the effect on SKBR-3 cell proliferation was greater than that in MDA-MB-231 cells (Fig. 5C). Considering SKBR-3 cells are Her2-overexpressing BC cells and MDA-MB-231 cells are triple-negative $\mathrm{BC}$ cells, we hypothesized that $\mathrm{Kpn} \beta 1$ is closely related to Her2. Previous studies have highlighted Kpn 31 mediated Her2 nuclear entry in MCF-7/HER18 BC cells (5).

A study on the association between tumors and Her2 nuclear entry have recently increased. After Her2 nuclear entry, the transcription and expression of the ribosomal RNA (rRNA) transcription factor is accelerated, thus fostering BC protein translation and stimulating tumor proliferation and development (22). In another study, inhibition of Her2 nuclear entry reduced the expression of cyclin D1, thus decreasing the growth of BC cells (35). Therefore, we hypothesized that Kpn $\beta 1$ overexpression could increase Her2 nuclear entry, thus promoting BC proliferation, while Kpn $\beta 1-k n o c k d o w n$ could decrease this proliferation by blocking Her2 nuclear entry.

In this study, we identified that high expression of Kpn $\beta 1$ in $\mathrm{BC}$ often leads to poor prognosis and that Kpn $\beta 1$-knockdown markedly reduced SKBR-3 cell proliferation. Based on these findings, we believe that $\mathrm{Kpn} \beta 1$ is related to Her2 and its knockdown reduces Her2 nuclear entry. To our knowledge, this is the first study to report the expression of $\mathrm{Kpn} \beta 1$ and relevant pathological parameters in $\mathrm{BC}$, and the effect on its prognosis. Our results revealed that Kpn $\beta 1$ knockdown reduced cell proliferation in SKBR-3 cell lines, and elucidated the relationship between Kpn $\beta 1$ and Her2 and its effect on nuclear entry. We identified the potential mechanism involved in the effect of $\mathrm{Kpn} \beta 1$ on Her 2 overexpression in $\mathrm{BC}$ cell proliferation.

One study limitation was the statistical parameters used in this study. Atypical statistical parameters should be used in future studies. Furthermore, experiments on Kpn $\beta 1$ knockdown in affected BC cells after blocking Her2 nuclear entry have not been fully demonstrated and therefore warrant further study to further uncover the mechanism.

\section{Acknowledgements}

This study was supported by the National Natural Science Foundation of China (no. 81672596), Nantong Science and Technology Project (no. MS22015058) and Nantong University Innovation Project (YKC15085).

\section{References}

1. Parkin DM, Bray F, Ferlay J and Pisani P: Global cancer statistics, 2002. CA Cancer J Clin 55: 74-108, 2005.

2. Jemal A, Siegel R, Xu J and Ward E: Cancer statistics, 2010. CA Cancer J Clin 60: 277-300, 2010.

3. Nakielny S and Dreyfuss G: Transport of proteins and RNAs in and out of the nucleus. Cell 99: 677-690, 1999.

4. Chook YM and Blobel G: Karyopherins and nuclear import. Curr Opin Struct Biol 11: 703-715, 2001.

5. Giri DK, Ali-Seyed M, Li LY, Lee DF, Ling P, Bartholomeusz G, Wang SC and Hung MC: Endosomal transport of ErbB-2: Mechanism for nuclear entry of the cell surface receptor. Mol Cell Biol 25: 11005-11018, 2005.

6. Lo HW, Ali-Seyed M, Wu Y, Bartholomeusz G, Hsu SC and Hung MC: Nuclear-cytoplasmic transport of EGFR involves receptor endocytosis, importin beta1 and CRM1. J Cell Biochem 98: 1570-1583, 2006.

7. Zhen Y, Sørensen V, Skjerpen CS, Haugsten EM, Jin Y, Wälchli S, Olsnes S and Wiedlocha A: Nuclear import of exogenous FGF1 requires the ER-protein LRRC59 and the importins Kpno1 and Kpn $\beta 1$. Traffic 13: 650-664, 2012.

8. Mosammaparast $\mathrm{N}$ and Pemberton LF: Karyopherins: From nuclear-transport mediators to nuclear-function regulators. Trends Cell Biol 14: 547-556, 2004.

9. Altan B, Yokobori T, Mochiki E, Ohno T, Ogata K, Ogawa A, Yanai M, Kobayashi T, Luvsandagva B, Asao T, et al: Nuclear karyopherin- $\alpha 2$ expression in primary lesions and metastatic lymph nodes was associated with poor prognosis and progression in gastric cancer. Carcinogenesis 34: 2314-2321, 2013.

10. Grupp K, Habermann M, Sirma H, Simon R, Steurer S, Hube-Magg C, Prien K, Burkhardt L, Jedrzejewska K, Salomon G, et al: High nuclear karyopherin $\alpha 2$ expression is a strong and independent predictor of biochemical recurrence in prostate cancer patients treated by radical prostatectomy. Mod Pathol 27: 96-106, 2014.

11. Huang L, Wang HY, Li JD, Wang JH, Zhou Y, Luo RZ, Yun JP, Zhang Y, Jia WH and Zheng M: KPNA2 promotes cell proliferation and tumorigenicity in epithelial ovarian carcinoma through upregulation of c-Myc and downregulation of FOXO3a. Cell Death Dis 4: e745, 2013.

12. Pavlou MP, Dimitromanolakis A, Martinez-Morillo E, Smid M, Foekens JA and Diamandis EP: Integrating meta-analysis of microarray data and targeted proteomics for biomarker identification: Application in breast cancer. J Proteome Res 13: 2897-2909, 2014

13. Ikenberg K, Valtcheva N, Brandt S, Zhong Q, Wong CE, Noske A, Rechsteiner M, Rueschoff JH, Caduff R, Dellas A, et al: KPNA2 is overexpressed in human and mouse endometrial cancers and promotes cellular proliferation. J Pathol 234: 239-252, 2014. 
14. Hu ZY, Yuan SX, Yang Y, Zhou WP and Jiang H: Pleomorphic adenoma gene 1 mediates the role of karyopherin alpha 2 and has prognostic significance in hepatocellular carcinoma. J Exp Clin Cancer Res 33: 61, 2014.

15. Ma S and Zhao X: KPNA2 is a promising biomarker candidate for esophageal squamous cell carcinoma and correlates with cell proliferation. Oncol Rep 32: 1631-1637, 2014.

16. van der Watt PJ, Maske CP, Hendricks DT, Parker MI, Denny L, Govender D, Birrer MJ and Leaner VD: The karyopherin proteins, Crm1 and karyopherin beta1, are overexpressed in cervical cancer and are critical for cancer cell survival and proliferation. Int J Cancer 124: 1829-1840, 2009.

17. Zhang P, Garnett J, Creighton CJ, Al Sannaa GA, Igram DR, Lazar A, Liu X, Liu C and Pollock RE: EZH2-miR-30d-KPNB1 pathway regulates malignant peripheral nerve sheath tumour cell survival and tumourigenesis. J Pathol 232: 308-318, 2014.

18. Martens-de Kemp SR, Nagel R, Stigter-van Walsum M, van der Meulen IH, van Beusechem VW, Braakhuis BJ and Brakenhoff RH: Functional genetic screens identify genes essential for tumor cell survival in head and neck and lung cancer. Clin Cancer Res 19: 1994-2003, 2013.

19. van der Watt PJ, Stowell CL and Leaner VD: The nuclear import receptor Kpn $\beta 1$ and its potential as an anticancer therapeutic target. Crit Rev Eukaryot Gene Expr 23: 1-10, 2013.

20. Nordgard SH, Johansen FE, Alnaes GI, Bucher E, Syvänen AC, Naume B, Børresen-Dale AL and Kristensen VN: Genome-wide analysis identifies $16 \mathrm{q}$ deletion associated with survival, molecular subtypes, mRNA expression, and germline haplotypes in breast cancer patients. Genes Chromosomes Cancer 47: 680-696, 2008.

21. Ross JS and Fletcher JA: The HER-2/neu oncogene in breast cancer: Prognostic factor, predictive factor, and target for therapy. Oncologist 3: 237-252, 1998.

22. Li LY, Chen H, Hsieh YH, Wang YN, Chu HJ, Chen YH, Chen HY, Chien PJ, Ma HT, Tsai HC, et al: Nuclear ErbB2 enhances translation and cell growth by activating transcription of ribosomal RNA genes. Cancer Res 71: 4269-4279, 2011.

23. Gucalp A, Gupta GP, Pilewskie ML, Sutton EJ and Norton L: Advances in managing breast cancer: A clinical update. F1000Prime Rep 6: 66, 2014

24. Lu T, Bao Z, Wang Y, Yang L, Lu B, Yan K, Wang S, Wei H, Zhang $Z$ and Cui G: Karyopherin $\beta 1$ regulates proliferation of human glioma cells via Wnt $/ \beta$-catenin pathway. Biochem Biophys Res Commun 478: 1189-1197, 2016.

25. Wang S, Zhao Y, Xia N, Zhang W, Tang Z, Wang C, Zhu X and Cui S: KPN $\beta 1$ promotes palmitate-induced insulin resistance via NF- $\mathrm{B}$ signaling in hepatocytes. J Physiol Biochem 71: 763-772, 2015 .
26. Lee Y, Jang AR, Francey LJ, Sehgal A and Hogenesch JB: KPNB1 mediates PER/CRY nuclear translocation and circadian clock function. eLife 4: e08647, 2015.

27. Bennett SM, Zhao L, Bosard C and Imperiale MJ: Role of a nuclear localization signal on the minor capsid proteins VP2 and VP3 in BKPyV nuclear entry. Virology 474: 110-116, 2015.

28. Sun C, Yu Z, Wang Y and Tao T: The importin protein karyopherin- $\beta 1$ regulates the mice fibroblast-like synoviocytes inflammation via facilitating nucleus transportation of STAT3 transcription factor. Biochem Biophys Res Commun 471: 553-559, 2016.

29. Kuusisto HV and Jans DA: Hyper-dependence of breast cancer cell types on the nuclear transporter importin $\beta 1$. Biochim Biophys Acta 1853: 1870-1878, 2015.

30. Angus L, van der Watt PJ and Leaner VD: Inhibition of the nuclear transporter, $\mathrm{Kpn} \beta 1$, results in prolonged mitotic arrest and activation of the intrinsic apoptotic pathway in cervical cancer cells. Carcinogenesis 35: 1121-1131, 2014.

31. Kojima Y, Nakayama M, Nishina T, Nakano H, Koyanagi M, Takeda K, Okumura K and Yagita H: Importin $\beta 1$ protein-mediated nuclear localization of death receptor 5 (DR5) limits DR5/ tumor necrosis factor (TNF)-related apoptosis-inducing ligand (TRAIL)-induced cell death of human tumor cells. J Biol Chem 286: 43383-43393, 2011.

32. Kim YH, Ha S, Kim J and Ham SW: Identification of KPNB1 as a cellular target of aminothiazole derivatives with anticancer activity. ChemMedChem 11: 1406-1409, 2016.

33. van der Watt PJ, Ngarande E and Leaner VD: Overexpression of $\mathrm{Kpn} \beta 1$ and Kpna2 importin proteins in cancer derives from deregulated E2F activity. PLoS One 6: e27723, 2011.

34. Zhang P, Yang X, Ma X, Ingram DR, Lazar AJ, Torres KE and Pollock RE: Antitumor effects of pharmacological EZH2 inhibition on malignant peripheral nerve sheath tumor through the miR-30a and KPNB1 pathway. Mol Cancer 14: 55, 2015.

35. Cordo Russo RI, Béguelin W, Díaz Flaqué MC, Proietti CJ, Venturutti L, Galigniana N, Tkach M, Guzmán P, Roa JC, O'Brien NA, et al: Targeting ErbB-2 nuclear localization and function inhibits breast cancer growth and overcomes trastuzumab resistance. Oncogene 34: 3413-3428, 2015.

This work is licensed under a Creative Commons Attribution-NonCommercial-NoDerivatives 4.0 International (CC BY-NC-ND 4.0) License. 